\title{
Epidemiology and Management of Gynecological and Breast Cancers in the Two Reference Hospitals of Parakou, in North Benin
} \author{
Vodouhe $\mathbf{M V}^{\mathbf{1}}$ and Perrin $\mathbf{R X}^{3}$ \\ ${ }^{1}$ University-affiliated Hospital of the Department of Borgou/Alibori (CHUD-B/A) in Parakou, Bénin \\ ${ }^{2}$ University-affiliated Hospital, Ouémé/Plateau Department (CHUD-O/P) in Porto Novo, Bénin \\ ${ }^{3}$ University-affiliated Hospital, Lagune Mother and Child Department (CHU-MEL) in Cotonou, Bénin
}

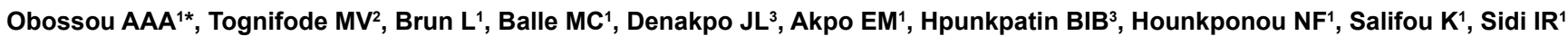

\begin{abstract}
Objective: It's aim at describing the epidemiological features and management modalities of gynecological and breast cancers in Parakou in 2016.

Framework and study method: It was a retrospective descriptive and analytical study covering a six-year period running from January 1, 2010 to December 31, 2015. It took place in Parakou at the University-affiliated Hospital of Borgou Department and at Boko Zone Hospital.

Results: Of the 90 cases of gynecological and breast cancers recorded during this period, cervical cancer was the leading one with $54.44 \%$. Breast cancer accounted for $34.44 \%$, followed by ovarian cancer $(5.57 \%)$. The median time from the onset of first symptoms to first consultation was $92 \pm 71$ days. The mean age of patients was $45 \pm 15.9$ years. Most cancers were diagnosed at an advanced stage (stage II, III or IV) that's $60.43 \%$. The most common anatomopathological types were: invasive ductal carcinomas $(67.74 \%)$ for the breast andinvasive squamous cell carcinomas for the cervix $(66 \%)$. Surgical treatment is always the only therapeutic mean available.
\end{abstract}

Conclusion: Gynecological and breast cancers are common in northern Benin. The treatment remains essentially surgical. It's necessary to promote the early detection of these pathologies.

Keywords: Gynecological and breast cancers; Epidemiology; Parakou; Benin

\section{Introduction}

Cancer is a major public health problem affecting all countries [1]. In 2012, the number of worldwide cancers new cases was 14.1 million, responsible for 8.2 million deaths [1]. According to GLOBOCAN, 32.6 million people (aged more than 15 years) were living with a cancer diagnosed during the five previous years. Moreover, the diagnosis and treatment of these cancers are too expensive for the patient, her family and the community. These cancers can affect women as well as men, adults and children. Gynecological, breast, colorectal, lung, stomach and liver cancers are among the most frequent cancers seen in women [2]. Gynecological and breast cancers play an important role in woman's tumorous pathology because of their frequency, severity and difficult management [3,4]. A retrospective study of cancer cases compiled in 2001 at Institut Curie in Dakar, revealed 507 cases of gynecological and breast cancers in women, out of the 786 representing the overall cancer cases received at the Institute during the same period. These cancers can affect the breast, cervix, endometrium, ovaries, vagina, vulva and the uterine tube. According to the World Health Organization (WHO), in 2013, out of 7.6 million of cancer-related deaths worldwide, 519,000 deaths were due to breast cancer and 260,000 deaths to cervical cancer [5].

In Africa, the situation is even more worrying due to: the increase in risk factors for cancer, the lack of organized screening, the discovery of the disease at advanced stages, the incomplete work-ups for extension and inadequate therapeutic management due to unmet therapeutic means including radiotherapy and certain chemotherapy molecules [6]. All these explain the particular gravity and prognosis of gynecological and breast cancers in Sub-Saharan African countries [5].

Fighting against gynecological and breast cancers thus appears to be one of the major challenges of reproductive health. This struggle involves the setting up of a cancer registry. We have decided to conduct this study on the epidemiology and management of gynecological and breast cancers in the two largest hospitals of North Benin in Parakou, so as to bring our support and contribution to the cancer strategy.

\section{Framework, Patients and Study Method}

It was a cross-sectional study with a descriptive and analytical purpose and a retrospective data collection covering a six-year period (from January 1, 2010 to December 31, 2015).

The study took place in the gynecological obstetrics and surgery departments of CHUD- Borgou/Alibori and at the maternity ward of Boko zone hospital, the two great hospitals of the biggest city of North Benin. The study covered all patients admitted for suspected gynecological or breast cancers during the period. Were also included, patients admitted for breast cancer, cervical cancer, endometrial cancer, ovarian cancer, vaginal cancer, vulvar cancer, fallopian tube cancer, with a diagnosis confirmed by anatomopathological examination and whose medical records were complete. Those whose records were unusable or whose cancer diagnosis was not confirmed by anatomopathological examination were excluded.

*Corresponding author: Obossou Awadé Afoukou Achille, University-affiliated Hospital of the Department of Borgou/Alibori (CHUD-B/A) in Parakou, Bénin, Tel: (229)-95853279/97067852; E-mail: awadefr2000@yahoo.fr

Received: June 22, 2017; Accepted: August 26, 2017; Published: August 29, 2017

Citation: Obossou AAA, Tognifode MV, Brun L, Balle MC, Denakpo JL, et al. (2017) Epidemiology and Management of Gynecological and Breast Cancers in the Two Reference Hospitals of Parakou, in North Benin. Oncol Cancer Case Rep 3: 133.

Copyright: (C) 2017 Obossou AAA, et al. This is an open-access article distributed under the terms of the Creative Commons Attribution License, which permits unrestricted use, distribution, and reproduction in any medium, provided the original author and source are credited. 
Citation: Obossou AAA, Tognifode MV, Brun L, Balle MC, Denakpo JL, et al. (2017) Epidemiology and Management of Gynecological and Breast Cancers in the Two Reference Hospitals of Parakou, in North Benin. Oncol Cancer Case Rep 3: 133.

We carried out a comprehensive census of all gynecological and breast cancer cases meeting the inclusion criteria during the study period. Data were collected from the consultation registers, hospital admissions, hospitalization, operating room, resuscitation unit, anatomopathology laboratory and patient records, using a form drawn up and previously tested for this purpose. Dependent variable was related to the existence of gynecological and breast cancer. Independent variables were related to socio-demographic characteristics, medical and gyneco-obstetric histories, clinical data, histological data and therapeutic data.

Data were entered and analyzed using the following softwares: EPI data and the French version of SPSS 21. For comparisons, we used the PIERSON chi-2 test. A difference was statistically considered as significant when $\mathrm{p} \leq 0.05$.

\section{Results}

\section{Incidence of gynecological and breast cancers}

Over the six-year period, we identified 90 cases of gynecological and breast cancers, including 86 cases in CHUD-B/A and 04 in HZB.

Cervical cancer and breast cancer were the two-main gynecologic and breast cancers identified in this study with respective rates of $54.44 \%$ and $34.44 \%$. Their distribution is shown in Table 1.

\section{Sociodemographic characteristics of patients}

Age of patients: The average age of patients was $45 \pm 15.9$ years with extreme ages of 13 years and 88 years. Gynecological and breast cancers were recorded in $3.33 \%$ of cases in patients under 20 years of age. These were two cases of breast cancer and one case of ovarian cancer. More than half of the patients who were suffering from cervical cancer were aged between 30 and 50 years old. The age distribution of patients is shown in Figure 1.

Educational attainment, occupation, marital status: In twothirds of the cases, patients were out-of -school. They were housewives in $68.89 \%$ of the cases, married in $91.11 \%$ of the cases. The distribution of patients according to educational background, occupation and marital status is shown in Table 2 .

Patient background: There were 6 nulliparous patients (6.67\%), 16 primiparous (17.77\%), 9 (10\%) pauciparous and 59 multiparous patients $(65.56 \%)$. Ten patients $(11.11 \%)$ were nursing mothers while $2(2.2 \%)$ were pregnant during the study. In $55.55 \%$ of cases, patients were aged 14 years old at their first menstruation. The menstrual cycle was regular in $52.22 \%$ of the cases. Contraception concept has been found in almost $49 \%$ of cases. However, the contraceptive method has not been specified in the files. HPV infection has been found in

\begin{tabular}{|c|c|c|c|c|c|c|}
\hline \multirow{2}{*}{ Type of Cancer } & \multicolumn{2}{|c|}{ CHUD/BA } & \multicolumn{2}{|c|}{ HZB } & \multicolumn{2}{c|}{ Total } \\
\cline { 2 - 7 } & $\mathbf{n}$ & $\%$ & $\mathbf{n}$ & $\%$ & $\mathbf{n}$ & $\%$ \\
\hline Cervical cancer & 45 & 50.00 & 4 & 4.44 & 49 & 54.44 \\
\hline Breast cancer & 31 & 34.44 & 0 & 0.00 & 31 & 34.44 \\
\hline Ovarian cancer & 5 & 5.57 & 0 & 0.00 & 5 & 5.57 \\
\hline Vulvar cancer & 2 & 2.22 & 0 & 0.00 & 2 & 2.22 \\
\hline Endometrial cancer & 2 & 2.22 & 0 & 0.00 & 2 & 2.22 \\
\hline $\begin{array}{c}\text { Ovarian+Cervical } \\
\text { cancer }\end{array}$ & 1 & 1.11 & 0 & 0.00 & 1 & 1.11 \\
\hline Total & 86 & 95.56 & 4 & 4.44 & 90 & 100 \\
\hline
\end{tabular}

Table 1: Distribution of patients according to the frequency of gynecological and breast cancers at the CHUD-B and the hospital zone of BOKO in Parakou from 2010 to 2015

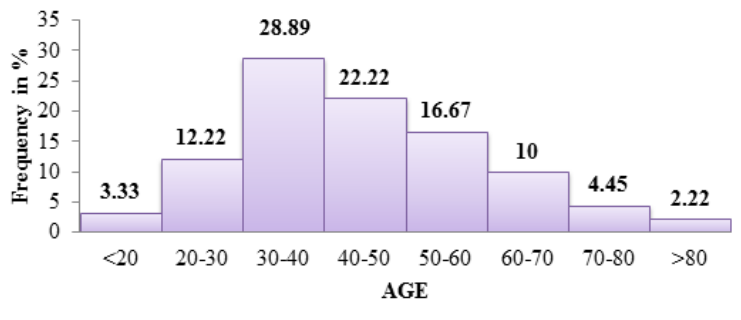

Figure 1: Age distribution of patients with gynecological and/or breast cancer in the CHUD-B and hospital zone of BOKO in Parakou from 2010 to 2015.

\begin{tabular}{|c|c|c|}
\hline Variables & Number & Proportion in \% \\
\hline \multicolumn{2}{|c|}{ Educational Background } \\
\hline Out-of-school & 60 & 66.67 \\
\hline Primary & 20 & 22.22 \\
\hline Secondary & 7 & 7.78 \\
\hline High level & 3 & 3.33 \\
\hline & Occupation/Profession \\
\hline Housekeeper & 62 & 68.89 \\
\hline Pupil/student & 4 & 4.44 \\
\hline Civil servant & 7 & 7.78 \\
\hline Tradeswoman/retailer & 12 & 13.33 \\
\hline Artisan & 5 & 5.56 \\
\hline & Marital status & \\
\hline Married & 82 & 91.11 \\
\hline Single & 4 & 4.44 \\
\hline Divorcee & 4 & 4.44 \\
\hline Total & 90 & 100.00 \\
\hline
\end{tabular}

Table 2: Distribution of patients with gynecological and/or breast cancer in the CHUD-B and zone hospital of BOKO in Parakou from 2010 to 2015, according to the level of education, occupation and the marital status.

8 patients (9\%) and 38 patients $(42.22 \%)$ were already menopausal. Tobacco consumption has been found in 4 patients so $4.44 \%$ of cases

\section{Clinical Characteristics}

Admission method, reason for admission and time from onset of first symptoms to first health care contact

Forty-one patients $(45.56 \%)$ were referred. The main reason for consultation of forty (40) patients $(44.44 \%)$ was induced metrorrhagia and 23 patients $(25.55 \%)$ were consulted for the existence of a breast nodule. These elements are detailed in Table 3.

\section{Macroscopic clinical form of cancers}

Budding tumors and ulcer necrotic tumors were the two main forms of cervical cancers in our study with respective frequencies of $18.36 \%$ and $4.08 \%$. For breast cancer, it was swelling $(22.58 \%)$ and ulceration (9.68\%). The macroscopic aspects of other cancers were not accurately documented. Table 4 shows the distribution of the macroscopic form of each cancer.

\section{Evolutionary stage}

Sixty-four percent (64\%) of the cervical cancers we identified were advanced cancer (stages II, III, IV). For the breast cancer, in $83.87 \%$ of cases, it was mainly tumors in stages I and II. All cases of ovarian cancer were already invasive cancers and were seen in stage IV.

\section{Histological Aspects of Gynecological and Breast Cancers}

Invasive ductal carcinoma, the most frequent histologic type of 
Citation: Obossou AAA, Tognifode MV, Brun L, Balle MC, Denakpo JL, et al. (2017) Epidemiology and Management of Gynecological and Breast Cancers in the Two Reference Hospitals of Parakou, in North Benin. Oncol Cancer Case Rep 3: 133.

Page 3 of 5

breast cancer has been recorded in 21 women (67.74\%) out of the total number of women with breast cancer, while among cervical cancer carriers, invasive squamous cell carcinoma was predominant in 33 Patients (66\%). These data are summarized in Table 5.

\section{Therapeutic Aspects of Gynecological and Breast Cancers}

Surgery was the only type of treatment performed in the patients of our series, that's in 39 patients meaning $43.33 \%$ of the cases. Thirteen

\begin{tabular}{|c|c|c|}
\hline Variables & Number & Proportion in \% \\
\hline \multicolumn{3}{|c|}{ Admission mode } \\
\hline Referred & 41 & 45.56 \\
\hline Arrived by her own & 49 & 54.44 \\
\hline \multicolumn{3}{|c|}{ Reason for admission } \\
\hline Induced metrorrhagia & 40 & 44.44 \\
\hline Leucorrhoea & 6 & 6.67 \\
\hline Dyspareunia & 1 & 1.11 \\
\hline Pelvic pain & 5 & 5.56 \\
\hline Pelvic tumor & 5 & 5.56 \\
\hline Vulvar tumor & 2 & 2.22 \\
\hline Breast lump & 23 & 25.55 \\
\hline Breast swelling & 7 & 7.78 \\
\hline Breast pain & 1 & 1.11 \\
\hline \multicolumn{3}{|c|}{ Time between first complaint and First consultation measured in days } \\
\hline $30-120$ & 43 & 47.78 \\
\hline $120-210$ & 41 & 45.56 \\
\hline $210-300$ & 3 & 3.33 \\
\hline $300-390$ & 3 & 3.33 \\
\hline Total & 90 & 100.00 \\
\hline
\end{tabular}

Table 3: Distribution of patients according to the mode of admission, the reason for admission and the median time between the onset of initial complaints and the first consultation.

\begin{tabular}{|c|c|c|}
\hline \multicolumn{2}{|c|}{ Variables Cervical Cancer $(\mathbf{n}=\mathbf{4 9})$} & Proportion \% \\
\hline \multicolumn{2}{|c|}{ Number } \\
\hline Ulcer necrotic tumor & 9 & 18.36 \\
\hline Invasive tumor & 5 & 10.20 \\
\hline Vegetative tumor & 2 & 4.08 \\
\hline \multicolumn{2}{|c|}{ Breast Cancer (n=31) } \\
\hline Swelling \\
\hline Ulceration & 7 & 4.08 \\
\hline Infiltration & 3 & 22.58 \\
\hline
\end{tabular}

Table 4: Distribution of gynecological cancer patients in CHUD-B and HZ of BOKO from 2010 to 2015 according to the macroscopic form of each cancer.

\begin{tabular}{|c|c|c|}
\hline Variables & Number & Proportion in \% \\
\hline \multicolumn{3}{|c|}{ Cervical cancer } \\
\hline Epidermoid Carcinoma in situ & 9 & 18.00 \\
\hline $\begin{array}{l}\text { Invasive squamous cell } \\
\text { carcinoma }\end{array}$ & 33 & 66.00 \\
\hline Verrucous carcinoma & 4 & 8.00 \\
\hline Invasive adenocarcinoma & 3 & 6.00 \\
\hline Inttrauterine sarcoma & 1 & 2.00 \\
\hline \multicolumn{3}{|c|}{ Breast cancer } \\
\hline Invasive ductal carcinoma & 21 & 67.74 \\
\hline Mucinous adenocarcinoma & 2 & 6.50 \\
\hline Medullary carcinoma & 1 & 3.22 \\
\hline $\begin{array}{l}\text { Invasive papillary } \\
\text { adenocarcinoma }\end{array}$ & 1 & 3.22 \\
\hline
\end{tabular}

\begin{tabular}{|c|c|c|}
\hline Adenosquamous carcinoma & 1 & 3.22 \\
\hline Papillary carcinoma & 3 & 9.67 \\
\hline Tubular carcinoma & 1 & 3.22 \\
\hline Sarcoma & 1 & 3.22 \\
\hline Endometrioid carcinoma & 3 & 50.00 \\
\hline Adenocarcinoma & 2 & 33.33 \\
\hline Undifferentiated carcinoma & 1 & 16.67 \\
\hline \multicolumn{2}{|c|}{ Endometrial cancer } \\
\hline Epidermoid carcinoma in situ & 1 \\
\hline Endometrioid carcinoma & 1 & 50.00 \\
\hline \multicolumn{2}{|c|}{ Vulvar cancer } \\
\hline Epidermoid carcinoma & 2 \\
\hline
\end{tabular}

Table 5: Distribution of gynecological cancer patients in CHUD-B and $\mathrm{HZ}$ of BOKO from 2010 to 2015 according to the histological type.

(13) patients (14.45\%) received breast lumpectomy, 4 (14.44\%) were given a simple mastectomy, $4(4.44 \%)$ received a mastectomy with dissection, 11 (12.22) were given a hysterectomy with preservation of adnexal mass, 4 (4.44\%) received a hysterectomy without preservation of adnexal mass and an ovarian lumpectomy. Alumpectomy of the vulva, and a Wertheim intervention were performed in each case, that's $1.11 \%$. Patients were treated neither with chemotherapy, nor with hormonotherapy or radiotherapy.

\section{Evolution and Prognosis}

Patients have been lost from sight in $96.67 \%$ of the cases and the remainder died (3.33\%)

\section{Discussion}

\section{Methodology discussion}

We carried out a retrospective study with a descriptive and analytical aim. This type of data collection involves biases related to missing data due to poor record keeping. In fact, out of 224 cases awaited, only 179 cases were found, including 89 unusable cases due to the lack of confirmation of the diagnosis. Thus, our work focused on 90 cases of gynecological and breast cancers.

\section{Frequency of gynecological and breast cancers}

Cervical cancer appeared to be the most frequent cancer in our series with a rate of $54.44 \%$ and breast cancer consists of $34.44 \%$ of cases.

Thirty or twenty years ago, epidemiological studies showed that cervical cancer was the most common form of gynecological and that breast cancer was the most common cancer in women living in developed countries $[7,8]$. But over the last decade or so, and given the changes in African lifestyles, which tend to westernize, breast cancer is the first gynecological and breast cancer in Africa and particularly in Benin. This is evidenced by the results of a study carried out in Cotonou in 2009 which revealed that the first three gynecological and breast cancers were respectively breast cancer (44.3\%), cervical cancer $(26.7 \%)$, and ovarian cancer (18.6\%) [3]. Similarly, in the series of Nayama, breast cancer ranked first with $40.4 \%$ followed by cervical cancer $(26 \%)$ [9]. Differences observed between these data and the rates we reported are difficult to analyze. They may be related to the large number of cases we have eliminated in our study. In developed countries with a cancer registry, the incidence of gynecological and breast cancers varies between $16.5 \%$ and $20.5 \%$ [10]. In developed countries, the mass screening policy, still known as organized screening, allowsto highlight a large number of breast cancers that would otherwise have been disregarded; thereby 
improvingthe management. This is the case in France where 52,000 cases of breast cancer are discovered each year [11].

\section{Socio-demographic characteristics}

The average age of patients was $45 \pm 15.9$ years; extreme ages being 13 years and 88 years. However, the age of patients varies according to the type of gynecological and breast cancers and according to the countries. An age over 50 is the main risk factor for breast cancer. The practical consequence is the age at which mass screening is done in these countries; 50 to 74 years [12-14]. But in Africa, according to epidemiological data, breast cancer occurs at early ages as it's the case in our study where most breast cancer patients were between 30 and 40 years of age [2-4]. The occurrence of breast cancer at these ages is an element of poor prognosis because it's, very often a genetic and very aggressive cancer [15-17].

For cervical cancer, the most numerous patients were aged 30 to 50 years, with a rate of $57.16 \%$. It's also a young woman related-cancer in Africa [2]. In the series of Nayama in Niger, most patients were aged between 25 and 54 years [9]. However, the main risk factor for cervical cancer was HPV infection. The retrospective nature of our study did not allow us to assess the impact of age at first sexual intercourse on the occurrence of cervical cancer. The low socioeconomic level is a real impediment to the prevention and management of these cancers, especially in Benin where patients with unfavorable socio-economic conditions do not have health insurance. It was conceded that cervical cancer was solely associated to women living in lower socioeconomic conditions and breast cancer would be more common in women of high socioeconomic conditions $[3,6,18]$. But the increasingly high frequency of breast cancer among disadvantaged social backgrounds in Africa has questioned these data.

In our series, $65.56 \%$ of patients have a parity greater than 3 . According to Dargent, multiparity and multiple pregnancies are continuously questioned in the genesis of cervical cancer [19]. Multiparity is a known risk factor for cervical cancer [20].

\section{Clinical and paraclinical aspects}

Clinical manifestations vary according to the type of cancer. Thus, for cervical cancer, patients sought medical attention for induced metrorrhagia in $44.44 \%$ of cases. This finding is inferior to those reported by Traore et al. [21] who found that $82.2 \%$ of induced metrorrhagia have resulted in medical consultation. Induced metrorrhagia is the most common physical sign of cervical cancer. In our series, in $18.36 \%$ of the cases, patients presented a uterine cervix with a budding aspect in our series. In our study, more than half of the cases are found in stages III and IV. Studies carried out in Mali, Cameroon and Benin have reported similar results $[3,21,22]$. We explain this by the late medical attendance and the lack of national organized screening system for cervical cancer. According to the literature, the late discovery rate has significantly decreased in developed countries where a well-structured screening program has been implemented $[23,24]$. Invasive squamous cell carcinoma was the most highly represented histological type in our study, with a frequency of $66 \%$, in accordance with international statistics. $[2,3,21]$.

As for breast cancer, the discovery of a breast lump by the patient is generally the usual reason for consultation [21]. This notion is found in our study for 23 cases that's $25.55 \%$ of our patients. We note that patients have been received for medical consultation in stages I or II, in 83.87\% of the cases for breast cancer. Also, Peng [25] in France reported that only $11 \%$ of breast cancers are discovered during stages III and
IV. Invasive ductal carcinomas are the most common types for breast cancer with $67.74 \%$. This rate is similar to the frequencies of invasive forms reported by other African authors [2,21].

\section{Therapeutic aspects}

In our study, the management of patients is limited to the surgical treatment associated with adjuvant medical treatment. Studies carried out in the sub-region have led to a similar result. The major problems in the management of these cancers in our regions are their discovery at the late stage. Indeed, at these stages, neo-adjuvant treatments, if available, remained inaccessible to our populations with such derisory resources of which a restricted number benefit from social services [4]. According to the literature, any suspicion of ovarian tumor should be explored surgically in operable patients [4].

\section{Prognosis}

The prognosis of these cancers is very poor in our study. The fact that our patients are mostly lost from our sight raises a particular problem in assessing the prognosis. Tonato Bagman et al. [3] report the same finding in their series.

\section{Conclusion}

The incidence of gynecological and breast cancers is relatively high in Parakou (Benin). The most affected organ is the cervix. Most patients came for medical consultation during cancer advanced stages (II, III, and IV). The medical care of patients is difficult because they consult very late and we don't have adequate and modern means to deal with this tragedy. Only surgical treatment, conceivable at a very early stage of the disease was possible; hence the need for prevention on the basis of screening.

\section{References}

1. Basette MT, Chokunonga E, Mauchaga B, Levy L, Ferley J, et al. (1995) Cancer in the African population in Harare, Zimbabwe, 1990-1992. Int J Cance 63: $29-36$

2. Amégbor K, Alfa AK, Darré T, Napo-Koura GA, Akpadza K (2011) Epidemiological and histopathological aspects of gynecological mammary cancers in Togo. Med Trop 71: 451-453.

3. Tonato JAB, Denakpo JL, Aguida B, Hounkpatin L, Lokossou A, et al. (2013) Epidemiology of the gynecological and mammary cancer to the HOMEL and in the CUGO Cotonou. Bénin. Bull Cancer 100: 141-146.

4. Dem A, Traoré B, Dieng MM (2008) Gynaecological and breast cancers at the Dakar cancer Institute, 2001-2008. Dakar Med 2: 126-134.

5. Sankaranarayanan R, Ferlay J (2006) Worldwide burden of gynaecological cancer: The size of the problem. Best Pract Res Clin Obstet Gynaecol 20: 207-225.

6. Bayo S, Kane S, Traoré C, Kamaté B, Dembele M, et al (2002) Cance incidence in five continents edited by Parkin DM, Whelan SL, Ferlay J, Teppo L, Thomas DB (eds). IARC Scientific Publications, France. 8(: 100-101.

7. Ferlay J, Shin HR, Bray F, Forman D, Mathers C, et al. (2010) GLOBOCAN 2008: v2.0, Cancer incidence and mortality worldwide: IARC Cancer Base No. 10. 2010. Lyon, France. International Agency for Research on Cancer.

8. Rochet Y, Lagarde C, Bremond A (1986) Cancers gynécologiques et mammaires. Encyclopédie des cancers dirigée par B. Hoermi. Flammarion. Med Sci 6: 255-263.

9. Nayama M, Nouhou H, Souna-Madougou K, Idi N, Garba M, et al. (2006) Cancers gynecologiques Et mammaires: Aspects epidemiologiques Et histologiques Dans Le Service D'anatomie Et Cytologie Pathologique De La Faculte Des Sciences Et De La Sante De Niamey Niger. Mali Medical 21: 43-49.

10. Laplanche A, Benhamou E (1991) Estimating the incidence of cancer. France Bull Cancer 78: 405-414 
Citation: Obossou AAA, Tognifode MV, Brun L, Balle MC, Denakpo JL, et al. (2017) Epidemiology and Management of Gynecological and Breast Cancers in the Two Reference Hospitals of Parakou, in North Benin. Oncol Cancer Case Rep 3: 133.

Page 5 of 5

11. Hélène Sancho-Garnier (2013) Épidémiologie des cancers gynécologiques : utérus, ovaire, vulve et vagin. Cancers gynécologiques pelviens 85 .

12. Abadie C, Aminot I, Dupuy E, Degré A (2002) Cancer du sein. Situation épidémiologique en Aquitaine, en 1999. Rev Med Ass Maladie 33: 173-181.

13. Ehud M, Yeouda E, Osnat T (1992) Aspiration and cytologic finding of surgical scar lesions in women with breast cancer. Cancer 69: 148-152.

14. Kemeny MM, Rivera DE, Terz JJ, Benfield JR (1986) Occult primary adenocarcinoma with axilary metastases. Am J Surg 152: 43-47.

15. Bourgeois JP (1990) Traitement du cancer du sein. Rev Prat 10: 914-916.

16. Piana L, Bonnier P (1992) Tumeurs du sein: Epidémiologie, dépistage, diagnostic, évolution, pronostic, principes du traitement. Rev Prat Paris 42: 1419-1423.

17. Rouesse J, Berlie J, Hacene K, Brunet, Spyratos F (1990) Facteurs épidémiologiques et pronostiques du cancer du sein. Rev Prat Paris 40: 909-913.

18. Peng J, Raverdy N, Ganry O, Goux F, Lorriaux A, et al. (1990) Épidémiologie descriptive des cancers gynécologiques et mammaires dans le département de la Somme (1984-1995). Rev Fr Gynecol Obstet 94: 327-332.
19. Dargent D (1990) Cancer du col de l'utérus. Épidémiologie, anatomie pathologique, diagnostic, évolution, principes de traitement, dépistage. Rev Prat Paris 49: 1923-1931.

20. Christine $\mathrm{H}$, Holschneider (2011) Premalignant and malignant disorders of the uterine cervix. Current diagnosis and treatment: Obstetrics and gynecology 48.

21. Traoré M, Diabaté FS, Diarra I, Mounkoro N, Traoré Y, et al. (2004) Cancers gynécologiques et mammaires: Aspects épidémiologiques et cliniques à l'hôpital du point G à Bamako. Mali Médical 19: 4-9.

22. Zacharie S, Jovanny TF, Florent YF, Jeanne HF, Emile TM, et al. (2014) Profil des cancers gynécologiques et mammaires à Yaoundé-Cameroun. Pan African Medical J 17: 28.

23. Michael L, Hicks, Ste Ven Pver (1991) How to Obtain an. Accurate Pap Smear. Medical Aspects of Human Sexuality 25: 36-43.

24. Amenssa GL, El-Idriss IF, Erchidi I, Melhouf A, Mrabet EL, et al. (2002) Mélanome malin primitif du col utérin. Press Méd 31: 976-978.

25. Peng J, Dubreuil A, Raverdy N, Ganry O, Lorriaux A (1997) Épidémiologie des cancers du sein dans la somme (période 1990-1993). Ann Chir 51: 974-980. 